\title{
Association of Demographic and Cancer-Specific Factors on Health Behavior Recommendations Specific to Cancer Prevention and Control Among Adolescent and Young Adult Survivors of Childhood Cancer
}

\author{
Katie Darabos, PhD, ${ }^{1}$ Lamia P. Barakat, PhD, ${ }^{1,2}$ Marilyn Schapira, MD, MPH, ${ }^{3}$ \\ Christine Hill-Kayser, MD, ${ }^{1,4}$ and Lisa A. Schwartz, PhD ${ }^{1,2}$
}

\begin{abstract}
Purpose: Adolescent and young adult survivors of childhood cancer (AYA) are at risk for long-term health problems that are exacerbated by not meeting health behavior recommendations (e.g., exercise). To identify AYA at risk for not meeting health behavior recommendations, we explored demographic (e.g., age) and cancer-specific (e.g., intensity of treatment) factors associated with not meeting specific health behavior recommendations that have implications for cancer prevention and control.

Methods: Regression (linear/binary) was used to examine demographic and cancer-specific associates regarding fruit/vegetable intake, binge drinking, sleep duration, sunscreen use, tobacco use, and physical activity among 307 AYA $\left(\mathrm{M}^{\mathrm{age}}=20.33\right.$, range $\left.=15-34\right)$ across three combined studies, treated at a pediatric cancer center. Health behavior measures were adapted from The Health Behaviors Survey and the Youth Risk Behavior Surveillance System questionnaire.

Results: AYA in general did not meet health behavior recommendations. Compared with AYA with public insurance, AYA with private insurance $(\beta=-0.19, p<0.01)$ were more likely to meet multiple health behavior recommendations. AYA at greatest risk for not meeting specific health behaviors were more likely to be diagnosed in middle childhood $\left(11.35^{\text {years }}\right)$ compared with early childhood $\left(8.38^{\text {years }}\right)$, be closer to diagnosis $\left(8.77^{\text {years }}\right.$ vs. $\left.11.76^{\text {years }}\right)$ and closer to treatment completion $\left(6.97^{\text {years }}\right.$ vs. $\left.9.91^{\text {years }}\right)$, and have a solid tumor $(32.7 \%)$ compared with a brain tumor $(10.6 \%)$.

Conclusion: Not meeting health behavior recommendations is common among AYA survivors of childhood cancer. Early education in the context of survivorship care is critical to provide teachable moments to AYA; such interventions might impact future long-term health and reduce risk for secondary cancers.
\end{abstract}

Keywords: health behaviors, diet, substance use, sleep, sunscreen, exercise

\section{Introduction}

W ITH A GROWING population of adolescent and young adult survivors of childhood cancer (AYA), attention toward health promotion to maximize long-term well-being has also increased. ${ }^{1}$ Indeed, AYA are at increased risk for poor long-term health outcomes owing to effects of cancer treatment, and secondary cancers. ${ }^{2-4}$ Following health behavior recommendations for positive health behaviors, such as adequate physical activity and healthy eating, may reduce such risk and promote quality of life. ${ }^{5}$ Despite research suggesting that AYA understand their increased risk for health complications and express a desire to improve health behaviors, many AYA report not meeting established health behavior recommendations, ${ }^{6,7}$ displaying unhealthy patterns of fruit/vegetable intake, binge drinking, sleep duration, sunscreen use, tobacco use, and physical activity. Therefore, it is crucial to understand factors that influence suboptimal health risk (e.g., substance use) and health-promoting (e.g., exercise) recommendations associated with cancer prevention and control.

Although no unifying theory of engagement with health behavior recommendations among AYA has been tested, a variety of modifiable factors have been examined. ${ }^{8-10}$ For example, established theories (e.g., Health Belief Model, Socioecological Model) ${ }^{11,12}$ indicate importance of

\footnotetext{
${ }^{1}$ The Children's Hospital of Philadelphia, Philadelphia, Pennsylvania, USA.

Departments of ${ }^{2}$ Pediatrics, ${ }^{3}$ Medicine, and ${ }^{4}$ Radiation Oncology, Perelman School of Medicine of the University of Pennsylvania, Philadelphia, Pennsylvania, USA.
} 
modifiable variables (i.e., health vulnerability), as associates of health promotion. However, there is also a need to understand how nonmodifiable factors are associated with health behaviors. AYA have little to no control over nonmodifiable factors, which includes sociodemographic (e.g., age, race/ethnicity, sex, socioeconomic status [SES]) and cancer-specific factors (e.g., tumor type, intensity of treatment). Understanding nonmodifiable factors, which are readily known to a provider, may help to identify AYA at risk of not meeting health behavior recommendations in clinical settings.

Indeed, there is growing recognition that various nonmodifiable factors are consistently associated with meeting or not meeting health behavior recommendations among AYA. Cross-sectional studies suggest that AYA of lower SES, who identify as Black, or diagnosed with leukemia or central nervous system disease are less likely to meet certain health behavior recommendations. ${ }^{8}$ One study on young adult cancer survivors ${ }^{9}$ yielded three distinct health behavior risk profiles (high, moderate, and low) and found that men were more likely to be members of the high-risk cluster (i.e., binge drinkers, current smokers, more past-year sexual partners, less physically active) compared with other risk clusters, whereas those in the moderate-risk cluster (i.e., less physically active) compared with the other risk clusters were more likely to be women, and were further from diagnosis. Those young adults in the low-risk cluster (i.e., low alcohol and tobacco use, fewer sexual partners) compared with other risk clusters tended to be younger and more recently diagnosed compared with the other risk clusters. ${ }^{9}$

However, previous research is limited by only focusing on certain health risk (e.g., alcohol and tobacco use) and/or health promoting behaviors (e.g., fruit/vegetable intake, physical activity) precluding the ability to tailor interventions specific to health behaviors associated with cancer prevention and control for subgroups of AYA that share common nonmodifiable factors. It may be that there are clusters of factors, providing relevant targets for intervention, associated with uptake of health behavior recommendations across multiple health behaviors. In turn, this may facilitate the identification of at-risk subgroups of AYA that share common nonmodifiable factors (e.g., younger AYA diagnosed with a solid tumor receiving a high intensity of treatment). Indeed, the clinic setting provides opportunities for teachable moments with AYA with cancer histories to communicate health behavior information with the potential to improve health behaviors in meaningful ways over time. ${ }^{13}$

More work is needed specifically focusing on AYA survivors as this developmental period is marked by rapidly developing physical, cognitive, emotional, and social maturation, ${ }^{4,15}$ such that suboptimal health behaviors might be more prevalent during this time period. Furthermore, the AYA period is a time of emerging health habits and experimentation with risk behaviors, providing a critical period for intervention before poor health behaviors are solidified. Therefore, the aim of this study was to fill a gap by examining associations of demographic and cancer-specific factors with specific health behavior recommendations important for cancer prevention and control among AYA survivors of childhood cancer treated at a pediatric cancer center. Based on previously published findings, we hypothesized that older AYA, AYA further from diagnosis, and AYA with public insurance would be less likely to meet health behavior recommendations.

\section{Methods}

\section{Data sources}

Data were aggregated across three studies of AYA childhood cancer survivors from authors (L.P.B., M.S., L.A.S.). All data included baseline assessment of health behaviors and shared similar eligibility criteria, enrollment protocols, and assessment procedures. Aggregating data ensured adequate sample size to conduct analyses. Study $1(n=49)$ was a text-messaging intervention intended to enhance selfmanagement for AYA (12-25 years) within a year off treatment with baseline data collected between 2014 and $2015 .^{16}$ Study $2(n=227)$ was an randomized control trial of a mHealth intervention designed to improve self-management among AYA (15-29 years) at least 2 years off treatment with baseline data collected between 2017 and 2019. ${ }^{17}$ Study 3 $(n=31)$ was designed to evaluate the long-term economic impact of treatment on a cancer clinical trial among AYA survivors (18-29 years) of childhood leukemia with baseline data collected between 2016 and $2017 .{ }^{18}$ Although there were time gaps in study enrollment across the three studies, health behavior recommendations remained unchanged across enrollment periods. Participants across studies were patients of the same institution and spoke English; samples were mutually exclusive (i.e., no overlapping participants in these studies). Participants were excluded if they were cognitively impaired. The study protocol was approved by the Institutional Review Boards of the Children's Hospital of Philadelphia and the University of Pennsylvania.

\section{Measures}

Demographic and cancer-related factors. Self-reported demographic factors included sex, age at survey, race, ethnicity, and health insurance status at survey completion. Cancer-specific factors, through medical chart review, included age at diagnosis, time since diagnosis, time since treatment completion, cancer type, history of relapse, and intensity of treatment as measured by the Intensity of Treatment Rating Scale 3.0. ${ }^{19}$

Health behavior outcome measures. Six health behaviors related to cancer control, completed by the AYA, were measured using The Health Behaviors Survey ${ }^{20}$ and questions adapted from the Youth Risk Behavior Surveillance System questionnaire. ${ }^{21}$ Survey items evaluated: fruit/ vegetable intake, binge drinking, sleep duration, sunscreen use, tobacco use, and physical activity. All health behaviors were dichotomized into meeting vs. not meeting health behavior recommendations. Health behavior achievement criteria are given in Table 1. Criteria were derived from cancer-specific, measurable guidelines (i.e., American Cancer Society, Children's Oncology Group) and resources from the U.S. government (i.e., Centers for Disease Control and Prevention, National Sleep Foundation). ${ }^{22-28}$

Health behavior composite. To capture demographic/ medical risk factors that might be associated with those AYA who are generally not consistently following health behavior recommendations, a total health behavior composite score was calculated by summing the number of health behavior recommendations AYA were not meeting, based on the 
Table 1. Health Behavior Recommendation Criteria

\begin{tabular}{|c|c|c|c|}
\hline Health behavior & Recommendation criteria & Survey item & Engagement criteria \\
\hline $\begin{array}{l}\text { Fruit/vegetable } \\
\text { intake }\end{array}$ & $\begin{array}{l}\text { The Dietary Guidelines for } \\
\text { Americans recommends } \\
2.5 \text { cups of vegetables and } \\
2 \text { cups of fruit per day }\end{array}$ & $\begin{array}{l}\text { "How many servings of fruits } \\
\text { and vegetables do you usually } \\
\text { eat each day?", (No servings to } \\
5 \text { or more servings) }\end{array}$ & $\begin{array}{l}\text { Meeting recommendations: } \\
3-4 \text { servings, } 5 \text { or more } \\
\text { servings; not meeting } \\
\text { recommendations: no } \\
\text { servings, } 1-2 \text { servings }\end{array}$ \\
\hline Binge drinking & $\begin{array}{l}\text { The Centers for Disease Control } \\
\text { categorizes binge drinking as } \\
\text { having } \geq 4 \text { drinks (females) } \\
\text { and } \geq 5 \text { drinks (males) in one } \\
\text { sitting }\end{array}$ & $\begin{array}{l}\text { "During the past } 14-30 \text { days, } \\
\text { how many times, did you } \\
\text { drink } 4 \text { (female) } / 5 \text { (male) or } \\
\text { more drinks of any kind of } \\
\text { alcohol in about two hours?" }\end{array}$ & $\begin{array}{l}\text { Meeting recommendations: } \\
<4 \text { drinks for females and } \\
<5 \text { drinks for males; not } \\
\text { meeting recommendations: } \\
\geq 4 \text { drinks for females and } \\
\geq 5 \text { drinks for males }\end{array}$ \\
\hline Sleep duration & $\begin{array}{l}\text { The National Sleep Foundation } \\
\text { recommends } 8-10 \text { hours per } \\
\text { night for adolescents and } \\
7-9 \text { hours for young adults }\end{array}$ & $\begin{array}{l}\text { "On average, how many hours } \\
\text { of sleep do you get in a } \\
\text { 24-hour period?", }\end{array}$ & $\begin{array}{l}\text { Meeting recommendations: } \\
\text { between } 8 \text { and } 10 \text { hours for } \\
\text { adolescents and } 7-9 \text { hours for } \\
\text { young adults; not meeting } \\
\text { recommendations: }<8 \text { hours } \\
\text { for adolescents and }<7 \text { hours } \\
\text { for young adults }\end{array}$ \\
\hline Sunscreen use & $\begin{array}{l}\text { The American Academy of } \\
\text { Dermatology recommends } \\
\text { that individuals wear } \\
\text { sunscreen every day, } \\
\text { if outside }\end{array}$ & $\begin{array}{l}\text { "Do you use sunscreen?" } \\
\text { (rarely to always) }\end{array}$ & $\begin{array}{l}\text { Meeting recommendations: } \\
\text { always; most of the time; } \\
\text { when out in the sun for an } \\
\text { extended period of time; not } \\
\text { meeting recommendations: } \\
\text { rarely; sometimes; never; only } \\
\text { war sunscreen when at the } \\
\text { pool or beach }\end{array}$ \\
\hline Tobacco use & $\begin{array}{l}\text { The Centers for Disease Control } \\
\text { recommend that individuals } \\
\text { refrain from any cigarette } \\
\text { use }^{27}\end{array}$ & $\begin{array}{l}\text { "Do you now smoke } \\
\text { cigarettes?", (Every day; } \\
\text { some days; not at all) }\end{array}$ & $\begin{array}{l}\text { Meeting recommendations: not } \\
\text { at all; not meeting } \\
\text { recommendations: everyday, } \\
\text { some days }\end{array}$ \\
\hline $\begin{array}{l}\text { Physical } \\
\text { activity }\end{array}$ & $\begin{array}{l}\text { The American Cancer Society } \\
\text { and the U.S. Department of } \\
\text { Health and Human Services } \\
\text { recommends that cancer } \\
\text { survivors and healthy } \\
\text { individuals engage in regular } \\
\text { physical activity and to aim to } \\
\text { exercise at least } 150 \text { minutes } \\
\text { per week }\end{array}$ & $\begin{array}{l}\text { "In a typical week, on how many } \\
\text { days do you do (1) vigorous- } \\
\text { intensity and (2) moderate- } \\
\text { intensity sports, fitness or } \\
\text { recreational activities for at } \\
\text { least } 10-15 \text { minutes?" }\end{array}$ & $\begin{array}{l}\text { Responses were weighted and } \\
\text { summed to create a modified } \\
\text { Leisure Index Score }{ }^{29} \text { into } \\
\text { active, moderately, } \\
\text { insufficiently active; meeting } \\
\text { recommendations: active, } \\
\text { moderately active; not } \\
\text { meeting recommendations: } \\
\text { insufficiently active }\end{array}$ \\
\hline
\end{tabular}

above recommendations. Higher scores represented more health behavior recommendations not being met. The health behavior composite score affords the ability to determine potential subgroups of AYA that might be more at risk of not meeting most health behavior recommendations and thus might be more susceptible to late effects and secondary cancers.

\section{Data analytic plan}

Descriptive analyses included frequencies, means, and standard deviations (SDs) to describe the study population. Health behavior outcomes variables were dichotomized by meeting health behavior recommendations (coded 0) compared with those not meeting health behavior recommendations (coded 1) for all health behaviors (fruit/vegetable intake, binge drinking, sleep duration, sunscreen use, tobacco use, and physical activity). Limitations in the way the physical activity question was asked to AYA precluded the ability to accurately estimate exact number of minutes exercised per week. Therefore, based on American Cancer Society recommendations to avoid inactivity and engage in regular physical activity we classified active and moderately active as meeting recommendations versus insufficiently active as not meeting recommendations based on the Leisure Score Index, which is a commonly used index score in oncology research for ranking cancer survivors from the lowest to highest levels of physical activity. ${ }^{29}$

Six separate binary logistic regression models were conducted to examine the influence of demographic and cancer-specific factors on health behaviors. Multiple linear regression was conducted to examine the influence of demographic and cancer-specific factors on meeting health behavior recommendations as a composite total score. Adjusted measures of effect size (Nagelkerke $R^{2}$ [logistic regression] adjusted $R^{2}$ [multiple regression]) are reported for each model. The Nagelkerke $R^{2}$ was chosen as this statistic has properties more similar to the $R^{2}$ statistic used in multiple regression. Variables in each model included demographic variables of sex (male vs. female), age at survey, race (minority vs. non-Hispanic White), ethnicity (Hispanic vs. non-Hispanic), and health insurance (public vs. private) age at diagnosis, time since diagnosis, time since treatment 
completion, cancer type (leukemia/lymphoma, solid tumor, brain tumor), history of relapse, and intensity of treatment. Post hoc analyses examined associates of demographic and cancer-specific factors between those AYA meeting all heath behavior recommendations versus those AYA not meeting all health behavior recommendations through independent samples $t$-test, chi-square analyses, and one-way analysis of variance.

A priori power analyses, with $n=98$ as the smallest possible sample size at $80 \%$ power to detect moderate to large effects given an alpha of 0.05 , suggested that we were adequately powered given our sample size. Results are presented by health behavior and then overall regression model.

\section{Results}

\section{Demographics and health behavior recommendations}

Demographic characteristics of the study sample are given in Table 2. On average, AYA were 20 years old $(\mathrm{SD}=3.37)$, with an almost equal percentage of women (46.9\%) and men $(53.1 \%)$. The majority of participants identified as nonHispanic, White $(74.9 \%)$, and having private insurance $(86.0 \%)$. On average, AYA were 11 years old at time of cancer diagnosis $(\mathrm{SD}=6.25)$ and, on average, 9 years postdiagnosis $(\mathrm{SD}=6.13$ years). The most common cancer type was leukemia/lymphoma $(59.9 \%)$, the majority received chemotherapy $(94.8 \%)$, and over half received $>1$ cancer treatment $(63.5 \%)$. Majority of AYA met recommendations

Table 2. Demographic and Medical Characteristics of the Study Sample $(N=307)$

\begin{tabular}{|c|c|c|c|c|c|}
\hline Variable & $\mathrm{n}$ & $\%$ & $M$ & $S D$ & Range \\
\hline Current age & & & 20.33 & 3.37 & $15-34$ \\
\hline Age at diagnosis & & & 11.11 & 6.25 & $0-23$ \\
\hline \multicolumn{6}{|l|}{ Sex } \\
\hline Female & 144 & 46.9 & & & \\
\hline Male & 163 & 53.1 & & & \\
\hline \multicolumn{6}{|l|}{ Ethnicity } \\
\hline White & 230 & 74.9 & & & \\
\hline African American & 37 & 12.1 & & & \\
\hline Asian & 19 & 6.2 & & & \\
\hline $\begin{array}{l}\text { American Indian/ } \\
\text { Alaskan Native }\end{array}$ & 1 & 0.3 & & & \\
\hline Other Race & 20 & 6.5 & & & \\
\hline \multicolumn{6}{|l|}{ Ethnicity } \\
\hline Non-Hispanic & 273 & 88.9 & & & \\
\hline Hispanic & 34 & 11.1 & & & \\
\hline \multicolumn{6}{|l|}{ Insurance type } \\
\hline Private & 264 & 86.0 & & & \\
\hline Public & 43 & 14.0 & & & \\
\hline Intensity of treatment & & & 2.87 & 0.75 & $1-4$ \\
\hline Years since diagnosis & & & 9.34 & 6.13 & $0-24$ \\
\hline Years off treatment & & & 7.30 & 5.82 & $0-22$ \\
\hline \multicolumn{6}{|l|}{ Tumor type } \\
\hline Liquid & 184 & 59.9 & & & \\
\hline Solid & 97 & 31.6 & & & \\
\hline Brain & 26 & 8.5 & & & \\
\hline Experienced relapse & 42 & 13.7 & & & \\
\hline
\end{tabular}

$\mathrm{SD}$, standard deviation. for abstaining from binge drinking $(78.5 \%)$, tobacco use (93.8\%), for getting enough sleep $(65.0 \%)$, and being physically active $(62.3 \%)$, whereas sunscreen use $(55.4 \%)$ and fruit/vegetable intake $(32.9 \%)$ comprised a smaller, yet sizable, percentage of AYA meeting recommendations. AYA meeting all health behavior recommendations represented $10.6 \%$ of the study sample $(n=29)$, whereas AYA not meeting all recommendations represented $89.4 \%$ of the study sample $(n=245)$.

\section{Demographic and cancer-specific factors associated with health behaviors}

Fruit/vegetable intake. AYA not meeting fruit/vegetable intake recommendations were significantly less likely to have had a relapse (odds ratio $[\mathrm{OR}]=0.47$, 95\% confidence interval $[\mathrm{CI}]=0.21-1.02)\left(\right.$ Tables 3-5). Nagelkerke $R^{2}$ was 0.05 .

Binge drinking. Engaging in binge drinking was significantly associated with higher age at baseline $(\mathrm{OR}=1.89,95 \%$ $\mathrm{CI}=1.05-3.40)$, solid tumor diagnosis $(\mathrm{OR}=1.90$, 95\% $\mathrm{CI}=1.00-3.61)$ compared with a leukemia/lymphoma/brain tumor, and higher intensity of treatment $(\mathrm{OR}=0.60,95 \%$ $\mathrm{CI}=0.38-0.96)$. Nagelkerke $R^{2}$ was 0.16 .

Sleep duration. There were no statistically significant associations with sleep duration.

Sunscreen use. AYA identifying as female $(\mathrm{OR}=0.57$, 95\% CI $=0.34-0.95)$ and non-Hispanic White $(\mathrm{OR}=0.44$, $95 \% \mathrm{CI}=0.23-0.83$ ) were less likely to be at risk of engaging in unsafe sun protective habits. Nagelkerke $R^{2}$ was 0.22 .

Tobacco use. AYA engaging in tobacco use were significantly less likely to be female $(\mathrm{OR}=0.22,95 \% \mathrm{CI}=0.06-$ $0.79)$ and more likely to identify as White $(\mathrm{OR}=11.38,95 \%$ $\mathrm{CI}=1.24-104.77)$. Nagelkerke $R^{2}$ was 0.18 .

Physical activity. AYA not meeting physical activity recommendations were significantly less likely to identify as non-Hispanic $(\mathrm{OR}=0.28,95 \% \mathrm{CI}=0.12-0.68)$ and were further from completing treatment $(\mathrm{OR}=0.75,95 \% \mathrm{CI}=$ 0.60-0.93).

Health behavior composite score. Only having private insurance $(\beta=-0.19, p<0.01)$ was significantly associated with the health behavior composite score $[F(12,273)=1.97$, $p<0.01$, adjusted $\left.R^{2}=0.04\right]$.

\section{Post hoc analyses}

AYA not meeting all health behavior recommendations, compared with AYA that were, were significantly more likely to be diagnosed at an older age ( $\mathrm{M}^{\text {age }}: 11.35$ vs. 8.38; $p<0.05$ ), be closer to diagnosis ( $\mathrm{M}^{\text {years }}$ : 8.77 vs. 11.76 ; $p<0.05$ ), closer to treatment completion ( $\mathrm{M}^{\mathrm{years}}: 6.97 \mathrm{vs}$. 9.91; $p<0.05)$, and be diagnosed with solid tumors compared with brain tumors $(32.7 \%$ vs. $10.6 \%, p=0.05)$ (Table 6$)$.

A summary of findings across all analyses is given in Table 7 . 
Table 3. Binary Logistic Regression on Meeting Health Behaviors

\begin{tabular}{|c|c|c|c|c|c|c|c|c|c|c|}
\hline & \multicolumn{2}{|c|}{$\begin{array}{c}\text { Fruit/vegetable } \\
\text { intake }\end{array}$} & \multicolumn{2}{|c|}{ Binge drinking } & \multicolumn{2}{|c|}{ Sleep duration } & \multicolumn{2}{|c|}{ Sunscreen use } & \multicolumn{2}{|c|}{ Tobacco use } \\
\hline & $\operatorname{Exp}(B)$ & $95 \% C I$ & $\operatorname{Exp}(B)$ & $95 \% C I$ & $\operatorname{Exp}(B)$ & $95 \% C I$ & $\operatorname{Exp}(B)$ & $95 \% C I$ & $\operatorname{Exp}(B)$ & $95 \% C I$ \\
\hline Non-Hispanic & .59 & $0.24-1.44$ & 1.10 & $0.37-3.29$ & 1.15 & $0.52-2.56$ & 1.40 & $0.59-3.30$ & $0.27^{\mathrm{a}}$ & $0.06-1.28$ \\
\hline Female & 0.99 & $0.60-1.63$ & 0.87 & $0.48-1.58$ & 0.93 & $0.56-1.53$ & $0.57^{b}$ & $0.34-0.95$ & $0.22^{\mathrm{b}}$ & $0.06-0.79$ \\
\hline White & 1.09 & $0.57-2.09$ & 1.89 & $0.80-4.48$ & 0.66 & $0.35-1.24$ & $0.44^{\mathrm{b}}$ & $0.23-0.83$ & $11.38^{\mathrm{b}}$ & $1.24-104.77$ \\
\hline Private insurance & 0.68 & $0.30-1.55$ & 0.94 & $0.34-2.60$ & $0.49^{\mathrm{a}}$ & $0.23-1.05$ & 0.60 & $0.28-1.32$ & 0.56 & $0.12-2.55$ \\
\hline Baseline age & 1.22 & $0.88-1.69$ & $1.89^{\mathrm{b}}$ & $1.05-3.40$ & 1.30 & $0.83-2.06$ & $0.59^{\mathrm{a}}$ & $0.32-1.08$ & 1.11 & $0.68-1.82$ \\
\hline Age at diagnosis & 0.83 & $0.61-1.15$ & 0.64 & $0.35-1.15$ & 0.69 & $0.44-1.09$ & $1.81^{\mathrm{a}}$ & $0.98-3.33$ & 0.88 & $0.54-1.44$ \\
\hline Intensity of tx & $1.43^{\mathrm{a}}$ & $0.98-2.10$ & $0.60^{\mathrm{b}}$ & $0.38-0.96$ & 0.92 & $0.63-1.33$ & $0.70^{\mathrm{a}}$ & $0.47-1.03$ & 0.74 & $0.32-1.69$ \\
\hline Time since $\mathrm{dx}$ & 0.86 & $0.63-1.17$ & 0.63 & $0.34-1.17$ & 0.67 & $0.41-1.10$ & 1.69 & $0.90-3.18$ & 1.02 & $0.63-1.65$ \\
\hline Time off $t x$ & 0.95 & $0.83-1.10$ & 0.98 & $0.84-1.15$ & 1.05 & $0.90-1.22$ & 0.99 & $0.85-1.50$ & 0.84 & $0.66-1.07$ \\
\hline Relapse & $0.46^{\mathrm{b}}$ & $0.21-1.02$ & 1.54 & $0.60-3.99$ & 1.21 & $0.53-2.77$ & 0.93 & $0.40-2.19$ & 1.20 & $0.25-5.81$ \\
\hline Solid tumor & 1.31 & $0.74-2.30$ & $1.90^{\mathrm{b}}$ & $1.00-3.61$ & 0.90 & $0.51-1.59$ & 0.66 & $0.37-1.18$ & 1.01 & $0.30-3.46$ \\
\hline \multirow[t]{2}{*}{ Brain tumor } & 1.43 & $0.54-3.73$ & 0.94 & $0.28-3.09$ & 0.90 & $0.35-2.28$ & 0.89 & $0.35-2.27$ & 2.42 & $0.59-9.94$ \\
\hline & \multicolumn{2}{|c|}{$\begin{array}{c}\text { Nagelkerke } \\
R^{2}=0.05\end{array}$} & \multicolumn{2}{|c|}{$\begin{array}{c}\text { Nagelkerke } \\
R^{2}=0.16\end{array}$} & \multicolumn{2}{|c|}{$\begin{array}{c}\text { Nagelkerke } \\
R^{2}=0.08\end{array}$} & \multicolumn{2}{|c|}{$\begin{array}{c}\text { Nagelkerke } \\
R^{2}=0.22\end{array}$} & \multicolumn{2}{|c|}{$\begin{array}{c}\text { Nagelkerke } \\
R^{2}=0.18\end{array}$} \\
\hline
\end{tabular}

${ }^{\mathrm{a}} p<0.10 ;{ }^{\mathrm{b}} p<0.05$.

CI, confidence interval.

\section{Discussion}

Despite benefits of meeting health behavior recommendations as a means to reduce or mitigate risk for subsequent chronic health problems, ${ }^{2-4}$ in the present study, AYA struggled to engage with recommendations surrounding health behaviors related to cancer control and prevention. Our findings provide support to the growing literature ${ }^{5,8,30}$ suggesting that a sizable proportion of AYA survivors regularly drink, consume diets that are low in fruits and vegetables, are inactive, and have poor sleep and sun protective habits, whereas fewer AYA are current smokers.

Hypotheses related to demographic and cancer-specific associates of not meeting health behavior recommendations were partially supported. When health behaviors were treated continuously, we only found support for an association of health insurance that is likely an indicator of higher socioeconomic status and better access to care; AYA with public, compared with private, insurance were less likely to meet multiple health behavior recommendations. AYA not meeting all recommendations were more likely to be closer to diagnosis and treatment completion and diagnosed with cancer at an older childhood age. As early survivorship may be an influential time of continued health vulnerabilities and frequent contact with medical care, ${ }^{31}$ this is an optimal time for focused, teachable moments on promoting engagement in positive health behaviors. $^{13}$

It is encouraging that, relative to peers, levels of binge drinking and tobacco use among AYA in the present sample are comparable or lower than previously reported, ${ }^{32}$ but any use is risky among this population. ${ }^{33}$ Consistent with findings, previous AYA research has shown that older age and a solid tumor diagnosis is associated with greater substance use. ${ }^{34-36}$ Wenninger et al. ${ }^{37}$ found that AYA with solid tumors are more at risk for developing post-traumatic stress disorder as solid tumor survivors are more likely to be physically impaired and have outward indicators of a cancer history such as amputation or prosthetics. Therefore, it is

Table 4. Binary Logistic Regression on Meeting Health Behaviors

\begin{tabular}{|c|c|c|c|c|c|c|c|c|c|}
\hline & \multicolumn{3}{|c|}{ Sunscreen use } & \multicolumn{3}{|c|}{ Tobacco use } & \multicolumn{3}{|c|}{ Physical activity } \\
\hline & $\operatorname{Exp}(B)$ & $95 \% C I$ & $\mathrm{p}$ & $\operatorname{Exp}(B)$ & $95 \% C I$ & $\mathrm{p}$ & $\operatorname{Exp}(B)$ & $95 \% C I$ & $\mathrm{p}$ \\
\hline Non-Hispanic & 1.40 & $0.59-3.30$ & 0.45 & 0.27 & $0.06-1.28$ & $0.10^{\mathrm{a}}$ & 0.28 & $0.12-0.68$ & $0.01^{\mathrm{b}}$ \\
\hline Female & 0.57 & $0.34-0.95$ & $0.03^{\mathrm{b}}$ & 0.22 & $0.06-0.79$ & $0.02^{\mathrm{b}}$ & 1.39 & $0.81-2.41$ & 0.24 \\
\hline White & 0.44 & $0.23-0.83$ & $0.01^{\mathrm{b}}$ & 11.38 & $1.24-104.77$ & $0.03^{\mathrm{b}}$ & 1.21 & $0.59-2.50$ & 0.61 \\
\hline Private insurance & 0.60 & $0.28-1.32$ & 0.21 & 0.56 & $0.12-2.55$ & 0.45 & 0.47 & $0.20-1.10$ & $0.08^{\mathrm{a}}$ \\
\hline Baseline age & 0.59 & $0.32-1.08$ & $0.09^{\mathrm{a}}$ & 1.11 & $0.68-1.82$ & 0.67 & 0.74 & $0.34-1.65$ & 0.47 \\
\hline Age at diagnosis & 1.81 & $0.98-3.33$ & $0.06^{\mathrm{a}}$ & 0.88 & $0.54-1.44$ & 0.61 & 1.46 & $0.66-3.23$ & 0.35 \\
\hline Intensity of $t x$ & 0.70 & $0.47-1.03$ & $0.07^{\mathrm{a}}$ & 0.74 & $0.32-1.69$ & 0.47 & 1.34 & 0.90-1.99 & 0.15 \\
\hline Time since $\mathrm{dx}$ & 1.69 & $0.90-3.18$ & 0.11 & 1.02 & $0.63-1.65$ & 0.93 & 1.96 & $0.87-4.42$ & 0.11 \\
\hline Time off tx & 0.99 & $0.85-1.50$ & 0.90 & 0.84 & $0.66-1.07$ & 0.15 & 0.75 & $0.60-0.93$ & $0.01^{\mathrm{b}}$ \\
\hline Relapse & 0.93 & $0.40-2.19$ & 0.87 & 1.20 & $0.25-5.81$ & 0.82 & 0.66 & $0.27-1.59$ & 0.35 \\
\hline Solid tumor & 0.66 & $0.37-1.18$ & 0.16 & 1.01 & $0.30-3.46$ & 0.98 & 0.88 & $0.48-1.63$ & 0.70 \\
\hline \multirow[t]{2}{*}{ Brain tumor } & 0.89 & $0.35-2.27$ & 0.81 & 2.42 & $0.59-9.94$ & 0.22 & 1.21 & $0.47-3.15$ & 0.69 \\
\hline & \multicolumn{3}{|c|}{ Nagelkerke $R^{2}=0.22$} & \multicolumn{3}{|c|}{ Nagelkerke $R^{2}=0.18$} & \multicolumn{3}{|c|}{ Nagelkerke $R^{2}=0.15$} \\
\hline
\end{tabular}

${ }^{\mathrm{a}} p<0.10 ;{ }^{\mathrm{b}} p<0.05$. 
Table 5. Multiple Linear Regression, Health Behavior Composite Score

\begin{tabular}{lrcc}
\hline Variable & $B$ & $S E$ & $\beta$ \\
\hline Non-Hispanic & -0.40 & 0.24 & $-0.11^{\mathrm{a}}$ \\
Female & -0.14 & 0.15 & -0.06 \\
White & 0.01 & 0.20 & 0.00 \\
Private insurance & -0.61 & 0.23 & $-0.17^{\mathrm{b}}$ \\
Baseline age & -0.03 & 0.13 & -0.09 \\
Age at diagnosis & 0.08 & 0.13 & 0.42 \\
Intensity of treatment & -0.01 & 0.11 & -0.01 \\
Time since diagnosis & 0.14 & 0.13 & 0.76 \\
Time off treatment & -0.09 & 0.05 & $-0.46^{\mathrm{a}}$ \\
Relapse & -0.20 & 0.25 & -0.06 \\
Solid tumor & 0.07 & 0.16 & 0.03 \\
Brain tumor & 0.15 & 0.26 & 0.04 \\
& \multicolumn{3}{c}{$F(12,273)=1.97,{ }^{\mathrm{c}}$} \\
& \multicolumn{3}{c}{ adjusted $R^{2}=0.04$} \\
\hline
\end{tabular}

Higher health behavior composite score represents more health behavior recommendations not being met.

${ }^{\mathrm{a}} p<0.10 ;{ }^{\mathrm{b}} p<0.01 ;{ }^{\mathrm{c}} p<0.05$.

$\mathrm{SE}$, standard error.

possible that increased alcohol use is a means of coping with distress and negative body image. Indeed, qualitative work among AYA has supported this assumption with AYA citing that their cancer diagnosis had increased their substance use. It is noteworthy that AYA who received more intense cancer treatment were less likely to engage in binge drinking, which might reflect knowledge that intense treatments confer greater risk and promote sensibility to curtail drinking to promote health. Consistent with previous research, identifying as Caucasian was related to a greater likelihood of using tobacco, ${ }^{38,39}$ whereas contrary to other AYA samples, ${ }^{8,30}$ our results suggested that men, not women, were more likely to engage in tobacco use.

Findings for fruit and/or vegetable intake were generally consistent with previous research, which suggests that the majority of AYA are not meeting fruit/vegetable recommendations. ${ }^{8,40,41}$ Perhaps because low fruit and/or vegetable intake is so ubiquitous, ${ }^{8}$ few demographic and cancerspecific factors were associated with not meeting recommendations. Whereas low fruit/vegetable intake is a global concern, ${ }^{42}$ this pattern is concerning owing to the increased health vulnerability (i.e., cardiovascular disease, obesity) among AYA survivors. ${ }^{43}$ That AYA who relapsed were more likely to meet fruit/vegetable intake recommendations may indicate motivation for healthier eating to reduce cancer risk. Future studies should focus on educating all AYA about the importance of healthy eating and further on how to navigate barriers (e.g., lack of resources, social influences) to healthy eating ${ }^{5}$ as they represent additional challenges.

Whereas previous research suggests that $\sim 50 \%$ of AYA, or less, meet physical activity recommendations, ${ }^{44,45}$ close to two-thirds of AYA in our sample $(62.3 \%)$ met physical activity recommendations. Our results point to characteristics of AYA who are more likely to not be physically active, such as identifying as Hispanic, which is often associated with barriers to meeting physical activity recommendations in the

Table 6. Differences on Key Study Variables Among Adolescent and Young Adult Survivors of Childhood Cancer Meeting All Health Behavior Recommendations

\begin{tabular}{|c|c|c|c|c|c|c|c|}
\hline \multirow[b]{2}{*}{ Variable } & \multicolumn{3}{|c|}{$\begin{array}{l}\text { Not meeting all } \\
\text { recommendations }(\mathrm{n}=245)\end{array}$} & \multicolumn{3}{|c|}{$\begin{array}{l}\text { Meeting all } \\
\text { recommendations }(\mathrm{n}=29)\end{array}$} & \multirow{2}{*}{$\frac{\mathrm{p} \text {-for difference }}{\mathrm{a}}$} \\
\hline & $\mathrm{n}$ & $\%$ & Range & $\mathrm{n}$ & $\%$ & Range & \\
\hline Current age, M (SD) & 19.98 & 3.17 & & 20.14 & 3.36 & & 0.80 \\
\hline Age at diagnosis, $\mathrm{M}(\mathrm{SD})$ & 11.35 & 6.47 & & 8.38 & 5.99 & & 0.02 \\
\hline \multicolumn{8}{|l|}{ Sex } \\
\hline Female & 114 & 46.5 & & 18 & 62.1 & & 0.11 \\
\hline Male & 131 & 53.5 & & 11 & 37.9 & & \\
\hline \multicolumn{8}{|l|}{ Race } \\
\hline White & 183 & 74.7 & & 24 & 82.8 & & 0.34 \\
\hline Minority & 62 & 25.3 & & 5 & 17.2 & & \\
\hline Ethnicity & & & & & & & 0.43 \\
\hline Non-Hispanic & 216 & 88.2 & & 27 & 93.1 & & \\
\hline Hispanic & 29 & 11.8 & & 2 & 6.9 & & \\
\hline Insurance type & & & & & & & 0.09 \\
\hline Private & 208 & 84.9 & & 28 & 96.6 & & \\
\hline Public & 37 & 15.1 & & 1 & 3.4 & & \\
\hline Intensity of treatment, $M(\mathrm{SD})$ & 2.86 & 0.76 & & 2.90 & 0.82 & & 0.79 \\
\hline Years since diagnosis, $M(\mathrm{SD})$ & 8.77 & 6.31 & & 11.76 & 6.20 & & 0.02 \\
\hline Years off treatment, $\mathrm{M}$ (SD) & 6.97 & 5.95 & & 9.91 & 6.13 & & 0.01 \\
\hline Tumor type & & & & & & & 0.05 \\
\hline Liquid & 139 & 56.7 & & 14 & 48.3 & & \\
\hline Solid & 80 & 32.7 & & 15 & 51.7 & & \\
\hline Brain & 26 & 10.6 & & 0 & 0.0 & & \\
\hline Relapse & & & & & & & 0.58 \\
\hline Yes & 33 & 13.5 & & 5 & 17.2 & & \\
\hline No & 212 & 86.5 & & 24 & 82.8 & & \\
\hline
\end{tabular}

${ }^{\mathrm{a}} p$ Values based on independent samples $t$-tests for continuous variables, chi-square tests for categorical variables. 
Table 7. Summary of Findings Across Health Behaviors

\begin{tabular}{|c|c|c|c|c|c|c|c|c|}
\hline Variable & $\begin{array}{c}\text { Binge } \\
\text { drinking }\end{array}$ & $\begin{array}{c}\text { Fruit/ } \\
\text { vegetable } \\
\text { intake }\end{array}$ & $\begin{array}{c}\text { Sleep } \\
\text { duration }\end{array}$ & $\begin{array}{c}\text { Sunscreen } \\
\text { use }\end{array}$ & $\begin{array}{c}\text { Tobacco } \\
\text { use }\end{array}$ & $\begin{array}{c}\text { Physical } \\
\text { activity }\end{array}$ & $\begin{array}{c}\text { Composite } \\
\text { health } \\
\text { behavior }\end{array}$ & $\begin{array}{c}\text { Not meeting } \\
\text { health } \\
\text { behaviors }\end{array}$ \\
\hline Non-Hispanic & ns & ns & ns & ns & - & - & $\mathrm{ns}$ & ns \\
\hline Female & ns & ns & ns & - & - & ns & ns & ns \\
\hline Non-Hispanic White & ns & ns & ns & - & + & ns & ns & ns \\
\hline Private insurance & ns & ns & - & ns & ns & - & + & - \\
\hline Current age & + & $\mathrm{ns}$ & ns & - & ns & ns & ns & ns \\
\hline Age at diagnosis & ns & ns & ns & + & ns & ns & ns & + \\
\hline Intensity of treatment & - & + & ns & - & ns & ns & ns & ns \\
\hline Time since diagnosis & ns & ns & ns & ns & ns & ns & ns & - \\
\hline Time off treatment & ns & ns & ns & ns & ns & - & ns & - \\
\hline Relapse & ns & - & ns & ns & ns & ns & $\mathrm{ns}$ & ns \\
\hline Solid tumor ${ }^{\mathrm{a}}$ & + & $\mathrm{ns}$ & ns & ns & ns & ns & ns & + \\
\hline Brain tumor $^{\mathrm{a}}$ & ns & ns & ns & ns & ns & ns & ns & - \\
\hline
\end{tabular}

Health behaviors coded as: $0=$ meeting recommendations, $1=$ not meeting recommendations; not meeting health behaviors coded as: $0=$ meeting all health behavior recommendations, $1=$ not meeting all health behavior recommendations and $+/-$ representing direction of effect with + representing higher values and - representing lower values; for individual health behaviors: + indicates odds ratio $>1$ for individual health behaviors and a positive beta for the composite health behavior score; - indicates odds ratio $<1$ for individual health behaviors and a negative beta for the composite health behavior score; shaded boxes represent significant effects $(p<0.05)$, unshaded boxes with symbols represent marginal effects $(p<0.10)$.

${ }^{\text {a}}$ Physically active reference group.

ns, Not significant.

broader literature. ${ }^{46}$ Of interest, AYA not meeting physical activity recommendations were more likely to be further from treatment completion. The finding for decreased activity among AYA further from treatment completion is concerning given that exercise post-treatment has been shown to be effective in improving cardiorespiratory fitness and combating fatigue among adults. ${ }^{47,48}$

Consistent with earlier findings of AYA survivors on suboptimal sunscreen use, ${ }^{49,50}$ a little over half of the sample $(55.4 \%)$ reported wearing sunscreen always or most of the time when outside. That almost half were not regularly using sunscreen is concerning given that skin cancers are among the most common secondary cancers among AYA. ${ }^{51,52}$ Also consistent with sunscreen use findings in the general literature, ${ }^{53}$ greater use of sunscreen was reported by those AYA who identified as female and non-Hispanic white. Men tend to report more barriers to sunscreen use, such as inconvenience and expense associated with sun protective clothing, and rate skin damage caused by sun exposure to be less severe compared with women. ${ }^{54}$ Given these consistent disparities, future studies should aim to focus on men and ethnic minorities as a means of increasing sunscreen use.

Majority of AYA reported meeting sleep recommendations, based on the number of hours slept per night, aligning with earlier research. ${ }^{55,56}$ No significant demographic or cancer-specific associations were found for not meeting sleep recommendations. Previous research has suggested that diagnosis and treatment-related factors are associated with sleep behaviors, specifically childhood cancer survivors with soft-tissue sarcoma and those with a history of cranial radiation were more likely to experience sleep disturbances. ${ }^{56-58}$ We may have been hindered by focusing on only sleep duration, as previous studies have considered and utilized broader assessments of sleep disturbances. ${ }^{56-58}$

This study is not without limitations. First, variables assessed do not represent the full spectrum of targeted health behavior domains (e.g., not all aspects of diet or sleep measured). Furthermore, health behavior data were self-reported, inviting the possibility of recall bias or responses reflecting social desirability. Data are cross-sectional and causal interpretations cannot be established. In addition, demographic and clinical characteristics of the study sample limits generalizability as this study included few ethnic minorities or those with brain tumors. It should also be noted that certain nonmodifiable factors may be dependent on parent factors as well, for example, AYA might be covered under their parent/caregiver's insurance and access to adequate nutrition might be dependent on living situation, financial circumstances and/or the health behaviors associated with family members. Future research should aim to examine these influences on AYA's following health behavior guidelines. Notwithstanding these limitations, this study has several strengths.

The focus on both health protective (e.g., physical activity) and health risk (e.g., substance use) behaviors in current AYA survivors is a strength as these health behaviors collectively contribute to future cancer risk but rarely are studied in tandem, ultimately providing greater clarity into how to best support AYA survivors at different stages post-treatment and across multiple health behaviors. Moreover, health behavior data from this study were all self-reported by the AYA, which is a step beyond some childhood cancer studies that rely on parent report. Finally, the sample consisted of AYA treated at a pediatric cancer center, which warrants separate investigation as results from AYA treated in pediatric care might differ from those of AYA treated at a community or adult hospital; however, this might limit generalizability.

This study highlights a number of key factors that should be considered when delivering health behavior information to AYA and in designing health promotion interventions. Our results indicate the relevance of demographic and treatment- 
related variables in conferring risk for many cancer control health behaviors, although the associates are not consistent across behaviors. There is some indication that sociodemographic factors or treatment-related impairment are risk factors for less optimal engagement with cancer control behaviors. Findings inform the need for further investigation to clarify at-risk subgroups that might benefit from increased counseling on the importance of remaining engaged to health behavior recommendations, especially given AYA survivors represent a developmentally complex and medically vulnerable population needing focused care.

Increased education on promoting engagement with the myriad of health behaviors that contribute to future cancer risk and adverse heath events are needed, especially since AYA prefer this as a need. A recent study found that AYA with cancer are turning to the Internet to gain more information on diet and nutrition and exercise and fitness information. ${ }^{59}$ Similarly, the most commonly desired topic of health information advice among AYA was physical activity with diet following in importance. ${ }^{60}$ Findings of this study coupled with previous research necessitate a need for better support and resources that are geared toward AYA patients about enhancing health promoting behaviors and decreasing health risk behaviors before transitioning to survivorship oriented care.

However, AYA are often known to be less engaged in health care surveillance after treatment, ${ }^{61}$ so it is imperative to be able to use tools that meet AYA at their level to optimize engagement in health behaviors. A recent focus group among AYA survivors ${ }^{62}$ highlighted preferences for delivery of survivorship-oriented care. Preferences included the use of digital health tools (e.g., email, text messages, and patient portals) for sending and receiving health information, greater discussion with health care providers surrounding knowledge of late effects and side effects of cancer treatment, the need for psychosocial support around fear and uncertainty about health, and adapting models of health care to include greater inclusion of AYA developmental considerations (e.g., autonomy).

Furthermore, greater attention to the role of the health care provider in disseminating health promoting behaviors as teachable moments during a clinic visit is imperative. ${ }^{13}$ Given a cancer diagnosis, visits with health care providers represent special moments of opportunity to counsel AYA on both health risk and health-promoting behaviors that have implications for disease control. Often AYA feel that provider-related conversations focus on curing cancer that leads to a potential perceived lack of control over health. ${ }^{62}$ Providers can instead reference that increasing health promoting behaviors and decreasing health risk behaviors are a means to help control one's health and potentially decrease late effects and secondary cancers. In fact, provider recommendations are often cited as the number one predictor in engagement with health promoting decisions. ${ }^{63}$ However, inconsistent findings remain ${ }^{9,60}$ on whether AYA report that health care providers are addressing health behavior recommendations during a care visit. ${ }^{64}$ Therefore, optimizing health behaviors for AYA survivors will depend on enhancing provider knowledge of cancer prevention and control behaviors and related risk factors, including easily identifiable risk factors related to demographics and treatment history.

\section{Author Disclosure Statement}

No competing financial interests exist.

\section{Funding information}

This work was supported by grant U48 DP005053-02S1, "AYA Self-Management via Texting, Education \& Plans for Survivors," awarded by the Centers for Disease Control and Prevention Special Interest Project SIP15-001, "Economic Impact of Clinical Trials among Children Diagnosed with Cancer," awarded by the Centers for Disease Control and Prevention Special Interest Project SIP15-002, and The Department of Pediatrics Chair's Initiative, Children's Hospital of Philadelphia. The findings and conclusions in this report are those of the authors and do not necessarily represent the official position of the Centers for Disease Control and Prevention. K.D. is supported by a training grant from the National Cancer Institute (principal investigator: K.D., 4K00CA222727).

\section{References}

1. Oeffinger KC, Hudson MM. Long-term complications following childhood and adolescent cancer: foundations for providing risk-based health care for survivors. CA Cancer J Clin. 2004;54(4):208-36.

2. Diorio C, Lin M, Ginn E, Ladas EJ. Psychosocial determinants of physical activity and dietary behaviors in adolescents and young adults with cancer and survivors. Pediatr Blood Cancer. 2018;65(9):e27243.

3. Robison LL, Hudson MM. Survivors of childhood and adolescent cancer: life-long risks and responsibilities. Nat Rev Cancer. 2014;14(1):61-70.

4. Lown EA, Phillips F, Schwartz LA, et al. Psychosocial follow-up in survivorship as a standard of care in pediatric oncology. Pediatr Blood Cancer. 2015;62(S5):S514-84.

5. Wu YP, Yi J, McClellan J, et al. Barriers and facilitators of healthy diet and exercise among adolescent and young adult cancer survivors: implications for behavioral interventions. J Adolesc Young Adult Oncol. 2015;4(4): 184-91.

6. Mulhern RK, Tyc VL, Phipps S, et al. Health-related behaviors of survivors of childhood cancer. Med Pediatr Oncol. 1995;25(3):159-65.

7. Rabin C, Simpson N, Morrow K, Pinto B. Behavioral and psychosocial program needs of young adult cancer survivors. Qual Health Res. 2011;21(6):796-806.

8. Warner EL, Nam GE, Zhang Y, et al. Health behaviors, quality of life, and psychosocial health among survivors of adolescent and young adult cancers. J Cancer Surviv. 2016; 10(2):280-90.

9. Lowe K, Escoffery C, Mertens AC, Berg CJ. Distinct health behavior and psychosocial profiles of young adult survivors of childhood cancers: a mixed methods study. J Cancer Surviv. 2016;10(4):619-32.

10. Carretier J, Boyle H, Duval S, et al. A review of health behaviors in childhood and adolescent cancer survivors: toward prevention of second primary cancer. J Adolesc Young Adult Oncol. 2016;5(2):78-90.

11. McLaren L, Hawe P. Ecological perspectives in health research. J Epidemiol Community Health. 2005;59(1): 6-14.

12. Champion VL, Skinner CS. The Health Belief Model. In: Glanz K, Rimer BK, Viswanath K (eds). Health behavior 
and health education: Theory, research, and practice. San Francisco, CA: Jossey-Bass, 2008, pp. 45-65.

13. Mcbride CM, Ostroff JS. Teachable moments for promoting smoking cessation: the context of cancer care and survivorship. Cancer Control. 2003;10(4):325-33.

14. Patterson P, McDonald FE, Zebrack B, Medlow S. Emerging issues among adolescent and young adult cancer survivors. Semin Oncol Nurs. 2015;31(1):53-9.

15. Arnett JJ. Emerging adulthood: a theory of development from the late teens through the twenties. Am Psychol. 2000; 55(5):469-80.

16. Schwartz LA, Daniel LC, Henry-Moss D, et al. Feasibility and acceptability of a pilot tailored text messaging intervention for adolescents and young adults completing cancer treatment. Psychooncology. 2020;29(1): 164-72.

17. Schwartz LA, Psihogios AM, Henry-Moss D, et al. Iterative development of a tailored mHealth intervention for adolescent and young adult survivors of childhood cancer. Clin Pract Pediatr Psychol. 2019;7(1):31-43.

18. Schapira M, Stevens EM, Bailey C, et al. Mortality and late effects among pediatric cancer patients Treated on-trial versus off-trial: results of a matched cohort study. Cancer. 2020;126(15):3471-82.

19. Kazak AE, Hocking MC, Ittenbach RF, et al. A revision of the intensity of treatment rating scale: classifying the intensity of pediatric cancer treatment. Pediatr Blood Cancer. 2012;59(1):96-9.

20. Hocking MC, Schwartz LA, Hobbie WL, et al. Prospectively examining physical activity in young adult survivors of childhood cancer and healthy controls. Pediatr Blood Cancer. 2013;60(2):309-15.

21. Centers for Disease Control and Prevention. 2019. Youth Risk Behavior Survey. Accessed August 24, 2020 from: www.cdc.gov/YRBSS.

22. Kushi LH, Doyle C, McCullough M, et al. American Cancer Society Guidelines on nutrition and physical activity for cancer prevention: reducing the risk of cancer with healthy food choices and physical activity. CA Cancer J Clin. 2012;62(1):30-67.

23. US Department of Agriculture. Dietary guidelines for Americans. 2015-2020. Accessed August 24, 2020 from: http://health.gov/dietaryguidelines/2015/guidelines

24. Centers for Disease Control and Prevention. Binge drinking. 2019. Accessed August 24, 2020 from: https://www .cdc.gov/alcohol/fact-sheets/binge-drinking.htm

25. Hirshkowitz M, Whiton K, Albert SM, et al. National Sleep Foundation's sleep time duration recommendations: methodology and results summary. Sleep Health. 2015; 1(1):40-3.

26. American Academy of Dermatology. Sunscreen FAQs. 2020. Accessed August 24, 2020 from: https://www.aad.org/public/ everyday-care/sun-protection/sunscreen-patients/sunscreenfaqs

27. Centers for Disease Control and Prevention. Smoking \& tobacco use. 2020. Accessed August 24, 2020 from: https:// www.cdc.gov/tobacco/index.htm

28. US Department of Health Human Services. Physical activity guidelines for Americans, 2nd ed. 2019. Accessed August 24, 2020 from: https://health.gov/sites/default/files/ 2019-09/Physical_Activity_Guidelines_2nd_edition.pdf

29. Amireault S, Godin G. The Godin-Shephard Leisure-Time Physical Activity Questionnaire: validity evidence supporting its use for classifying healthy adults into active and insufficiently active categories. Percept Mot Skills. 2015; 120(2):604-22.

30. Kaul S, Veeranki SP, Rodriguez AM, Kuo YF. Cigarette smoking, comorbidity, and general health among survivors of adolescent and young adult cancer. Cancer. 2016; 122(18):2895-905.

31. Nathan PC, Ford JS, Henderson TO, et al. Health behaviors, medical care, and interventions to promote healthy living in the Childhood Cancer Survivor Study cohort. J Clin Oncol. 2009;27(14):2363.

32. Milam J, Slaughter R, Meeske K, et al. Substance use among adolescent and young adult cancer survivors. Psychooncology. 2016;25(11):1357-62.

33. Frobisher C, Winter DL, Lancashire ER, et al. Extent of smoking and age at initiation of smoking among adult survivors of childhood cancer in Britain. J Natl Cancer Inst. 2008;100(15):1068-81.

34. Frobisher C, Lancashire ER, Reulen RC, et al. Extent of alcohol consumption among adult survivors of childhood cancer: the British Childhood Cancer Survivor Study. Cancer Epidemiol Biomarkers Prev. 2010;19(5): 1174-84.

35. Lown A, Goldsby R, Mertens AC, et al. Alcohol consumption patterns and risk factors among childhood cancer survivors compared to siblings and general population peers. Addiction. 2008;103(7):1139-48.

36. Ruiz ME, Sender L, Torno L, Fortier MA. The associations of age and ethnicity on substance use behaviors of adolescent and young adult childhood cancer survivors. Psychooncology. 2016;25(10):1229-36.

37. Wenninger K, Helmes A, Bengel J, et al. Coping in longterm survivors of childhood cancer: relations to psychological distress. Psychooncology. 2013;22(4):854-61.

38. Tao ML, Guo MD, Weiss R, et al. Smoking in adult survivors of childhood acute lymphoblastic leukemia. J Natl Cancer Inst. 1998;90(3):219-25.

39. Ford JS, Barnett M, Werk R. Health behaviors of childhood cancer survivors. Children. 2014;1(3):355-73.

40. McCracken M, Jiles R, Blanck HM. Health behaviors of the young adult U.S. population: behavioral risk factor surveillance system, 2003. Prev Chronic Dis. 2007;4(2): A25.

41. Demark-Wahnefried W, Werner C, Clipp EC, et al. Survivors of childhood cancer and their guardians. Cancer. 2005;103(10):2171-80.

42. World Health Organization. Promoting fruit and vegetable consumption around the world. Accessed August 24, 2020 from: https://www.who.int/dietphysicalactivity/fruit/index 1 .html 2020.

43. Talvensaari KK, Lanning M, Tapanainen P, Knip M. Longterm survivors of childhood cancer have an increased risk of manifesting the metabolic syndrome. J Clin Encodrinol Metab. 1996;81(8):3051-5.

44. Ness KK, Leisenring WM, Huang S, et al. Predictors of inactive lifestyle among adult survivors of childhood cancer. Cancer. 2009;115(9):1984-94.

45. Devine KA, Mertens AC, Whitton JA, et al. Factors associated with physical activity among adolescent and young adult survivors of early childhood cancer: a report from the childhood cancer survivor study (CCSS). Psychooncology. 2018;27(2):613-9.

46. Amesty SC. Barriers to physical activity in the Hispanic community. J Public Health Policy. 2003;24(1): 41-58. 
47. Hayes SC, Spence RR, Galvao DA, Newton RU. Australian Association for Exercise and Sport Science position stand: optimising cancer outcomes through exercise. J Sci Med Sport. 2009;12(4):428-34.

48. Jacobsen PB, Donovan KA, Vadaparampil ST, Small BJ. Systematic review and meta-analysis of psychological and activity-based interventions for cancer-related fatigue. Health Psychol. 2007;26(6):660-7.

49. Coups EJ, Ostroff JS. A population-based estimate of the prevalence of behavioral risk factors among adult cancer survivors and noncancer controls. Prev Med. 2005;40(6): 702-11.

50. Hudson MM, Tyc VL, Srivastava DK, et al. Multicomponent behavioral intervention to promote health protective behaviors in childhood cancer survivors: the Protect Study. Med Pediatr Oncol. 2002;39(1):2-11.

51. Dickerman JD. The late effects of childhood cancer therapy. Pediatrics. 2007;119(3):554-68.

52. Perkins JL, Liu Y, Mitby PA, et al. Nonmelanoma skin cancer in survivors of childhood and adolescent cancer: a report from the Childhood Cancer Survivor Study. J Clin Oncol. 2005;23(16):3733-41.

53. Holman DM, Berkowitz Z, Guy GP, Jr., et al. Patterns of sunscreen use on the face and other exposed skin among US adults. J Am Acad Dermatol. 2015;73(1):83.e1-92.e1.

54. Kasparian NA, McLoone JK, Meiser B. Skin cancer-related prevention and screening behaviors: a review of the literature. J Behav Med. 2009;32(5):406-28.

55. Fisher RS, Rausch JR, Ferrante AC, et al. Trajectories of health behaviors across early childhood cancer survivorship. Psychooncology. 2019;28(1):68-75.

56. Daniel LC, Wang M, Mulrooney DA, et al. Sleep, emotional distress, and physical health in survivors of childhood cancer: a report from the Childhood Cancer Survivor Study. Psychooncology. 2019;28(4):903-12.

57. Mulrooney DA, Ness KK, Neglia JP, et al. Fatigue and sleep disturbance in adult survivors of childhood cancer: a report from the childhood cancer survivor study (CCSS). Sleep. 2008;31(2):271-81.

58. Van Someren E, Swart-Heikens J, Endert E, et al. Long-term effects of cranial irradiation for childhood malignancy on sleep in adulthood. Eur J Endocrinol. 2004;150(4):503-10.

59. Aggarwal R, Hueniken K, Eng L, et al. Health-related social media use and preferences of adolescent and young adult cancer patients for virtual programming. Support Care Cancer. 2020;28(10):4789-4801.

60. Pugh G, Hough RE, Gravestock HL, et al. The health behavior information needs and preferences of teenage and young adult cancer survivors. J Adolesc Young Adult Oncol. 2017;6(2):318-26.

61. Beaupin LK, DiGrande S. Survivorship care in AYA patients: battling the loss to follow-up. Am J Manag Care. 2018;24 (10 Spec No.):SP419-20.

62. Psihogios AM, Schwartz LA, Deatrick JA, et al. Preferences for cancer survivorship care among adolescents and young adults who experienced healthcare transitions and their parents. J Cancer Surv. 2019;13(4):620-31.

63. Ylitalo KR, Lee H, Mehta NK. Health care provider recommendation, human papillomavirus vaccination, and race/ethnicity in the US National Immunization Survey. Am J Public Health. 2013;103(1):164-9.

64. Berg C, Stratton E, Esiashvili N, et al. Providers' perspectives of survivorship care for young adult survivors of childhood cancer. J Cancer Educ. 2016;31(1):31-8.

Address correspondence to: Katie Darabos, PhD

The Children's Hospital of Philadelphia 3615 Civic Center Blvd, ARC 1427.29

Philadelphia, PA 19104

USA

Email: darabosk@email.chop.edu 